\title{
CYTOMORPHOLOGY OF THE BULBAR CONJUNCTIVAL CELLS IN PATIENTS WITH DRY EYE
}

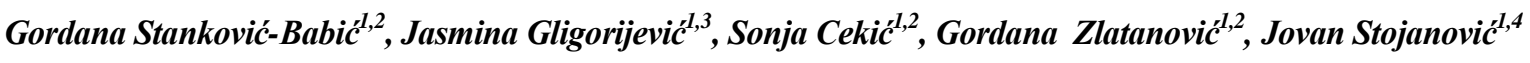 \\ ${ }^{1}$ University of Niš, Faculty of Medicine, Niš, Serbia \\ ${ }^{2}$ Clinical Center Niš, Ophthalmology Clinic, Niš, Serbia \\ ${ }^{3}$ Clinical Center Niš, Institute of Pathology, Niš, Serbia \\ ${ }^{4}$ Clinical Center Niš, Institute of Forensic Medicine, Niš, Serbia
}

\begin{abstract}
Dry eye is among the most common pathological conditions in ophthalmology. The aim of our study was to present possibilites of two different cytological methods for examination of cytomorphology of bulbar conjunctival cellsimpression cytology (IC) and combined cytological method for scanning electron microscopy in the diagnosis of dry eye (ICSEM). A hundred and twenty-two patients of both sexes, in different age groups, were analyzed by clinical method (slit lamp, Schirmer I, TBUT, Rose Bengal) and two cytomorphological methods - IC and ICSEM. In patients with dry eye, squamous metaplasia, inflammation and severe loss of adhesiveness of the epithelium were present. ICSEM gives an advantage in early diagnosis of changes, before the lesion of superficial conjunctival epithelium in patients with dry eye. The phenomenon of metaplasia appears in the epithelium of the bulbar conjunctiva in the absence of manifest dry eye and represents the basis for understanding the increased incidence of this syndrome in older patients with dry eye.
\end{abstract}

Key words: dry eye, impression cytology, cytological method for scanning electron microscopy.

\section{Introduction}

Dry eye is among the most common pathological conditions in ophthalmology [1].

According to the definition, it is a multifactorial disease of the tears and ocular surface that results in symptoms of discomforts, visual disabilities, unstable tear film and ocular surface damage potential [2]. Dry eye affects $2-14,4 \%$ of the tested population worldwide and it is more common among older people, especially among females. The dry eye is a result of various data obtained during several clinical and cytological diagnostic procedures [3-6].

Among the cytological methods of examination are conjunctival impression cytology (CIC) and a combined method of impression cytology and scanning electron microscopy (ICSEM). CIC is a noninvasive method of conjunctival biopsy which allows the examination of conjunctival changes at the cellular level, the etiology of various ocular surface disorders, documenting on age changes of ocular surface, monitoring the effects of the treatment of dry eye, staining of squamous metaplasia, and it contribute to the study of ocular surface diseases with immune histochemical and DNA analysis [7-10].

*Correspondence to: Gordana Stanković-Babić, M.D., PhD University of Niš, Faculty of Medicine, Clinical Center Niš Ophthalmology Clinic, 48 Dr Zoran Đinđić Blvd., Niš, Serbia Phone: +381641666176

E-mail: gordanasb@mts.rs

Received July $13^{\text {th }}, 2016$, accepted for publication January $29^{\text {th }}, 2017$
ICSEM shows the appearance of various types of conjunctival cells in three dimensions, as well as the appearance of apical cell surfaces and microvillus [11].

The aim of our study is to review the features of cytomorphology of bulbar conjunctival cell samples with CIC and ICSEM in patients with different dry eye etiology.

\section{Material and Methods}

After the approval of the local ethical committee, clinical and cytomorphological examination of 122 patients, out of which 100 by CIC and 22 by ICSEM, was conducted at the Ophthalmology Clinic and the Institute of Pathology, Clinical Centre Niš. The clinical methods of examination included slit lamp of anterior segment and tear layers, Schirmer test I, tear break-up time (TBUT), and Rose Bengal test. Cytomorphological examination of nasal and temporal parts of bulbar conjunctiva was done by CIC and ICSEM. All examined patients were divided into three categories, according to age: younger than 20 years, 21-40 years and older than 41 years.

Millipore membrane filter (Membrane-Filters, Whatman®, Schleicher\&Schuell, OE 66 St., Germany) is biologically inert, with submicroscopic pores. It is cut into $4 \mathrm{x} 4 \mathrm{~mm}$ squares and it gently lies on the previously anesthetized ocular surface (on the bulbar conjunctiva for both methods, temporal/nasal location for CIC and temporal for ICSEM) for several seconds and it adheres 
to the fine layer of the superficial conjunctival epithelium. The obtained imprint is then fixed, dyed and visualized using scanning electron microscopy.

CIC imprint - after air drying for 15 minutes, the preparations were fixed in $95 \%$ alcohol and stained using a modified method of hematoxylin eosin (HE) and periodic acid-Schiff (PAS) for cytological specimens. Cytological analysis was performed to show the score impression cytology (IC-score) for each tested sample, which was used for statistical analysis (Pearson's $\chi 2$ tests) of the contribution of individual parameters relevant for the assessment of dry eye.

ICSEM imprint was immersed in $2 \%$ glutaraldehyde solution. Cells were first fixed in $2 \%$ solution of glutaraldehyde for 24 hours, washed by being kept in the Millonigbuffer for $30 \mathrm{~min}$. Postfixation was performed in $1 \%$ OsO4, for 1.5 hours, and then the cells were washed two times for $30 \mathrm{~min}$ in Millonig buffer. The cells dehidratation was obtained by their imersion in the growing concentration of alcohol (50\%, 75\%, $95 \%$ and $100 \%$ ), each concentration for $15 \mathrm{~min}$ and dried out at a critical point. The samples were mounted on pillars and covered with gold and thus prepared cells were observed in the scanning electron microscope.

Histological and morphological analysis of conjunctive cells samples, isolated by CIC and ICSEM, was performed using the methodology reported in literature [8-11] and presented in Figures.

We used SPSS statistical package, version 15.0 for statistical analysis. Categorical characteristics are given as absolute numbers, and in percentages (\%).Pearsons $\chi^{2}$ test or Fisher test were also used as statistical procedures.

\section{Results}

A comparative analysis of cytomorphological features of bulbar CIC samples from 100 patients, 50 males and 50 females, was performed. There are no statistically significant differences in gender representation in age groups (Table 1). Diagnosis of dry eye was established in 65 patients (Table 2) older than 40 years with rheumatoid arthritis (RA), hypertension (HTA), and diabetes mellitus (DM) by the following clinical criteria: Schirmer $\mathrm{I} \leq 10$ $\mathrm{mm} / 5 \mathrm{~min}$; TBUT $\leq 10 \mathrm{sec}$; Rose Bengal positive, 3 of 4 per Bijsterveld. There is significant difference in health characteristics between genders $(\mathrm{p}<0.001)$ - Table 2 . Also, in group patients for ICSEM there are statistically significant difference in gender representation in age groups (Table 3 ).

Table 1 Distribution of respondents by gender and age for CIC

\begin{tabular}{lccc}
\hline \multirow{2}{*}{ Sex } & \multicolumn{2}{c}{ Age } & \multirow{2}{*}{ Total } \\
\cline { 2 - 3 } & $\leq 40$ years & $>40$ years & \\
\hline Male & $18(36.00 \%)$ & $32(64.00 \%)$ & 50 \\
Female & $17(34.00 \%)$ & $33(66.00 \%)$ & 50 \\
\hline Total & 35 & 65 & 100 \\
\hline$\chi^{2}=0,04, \mathrm{df}=1, \mathrm{p}=0,8348$ (n.s.) &
\end{tabular}

Table 2 Health characteristics of patients with dry eye for CIC

\begin{tabular}{lcccc}
\hline \multirow{2}{*}{ Sex } & \multicolumn{3}{c}{ Health characteristics } & \multirow{2}{*}{ Total } \\
\cline { 2 - 4 } & RA & HTA & DM & \\
\hline Male & 2 & 19 & 11 & 32 \\
& $(6.25 \%)$ & $(59.38 \%)$ & $(34.38 \%)$ & $(100.00 \%)$ \\
Female & 16 & 8 & 9 & 33 \\
& $(48.48 \%)$ & $(24.24 \%)$ & $(27.27 \%)$ & $(100.00 \%)$ \\
\hline Total & 18 & 27 & 20 & 65 \\
\hline
\end{tabular}

$\chi^{2}=15.56, \mathrm{df}=2, \mathrm{p}<0.001$

Table 3 Distribution by sex and age of patients for ICSEM

\begin{tabular}{lccc}
\hline \multirow{2}{*}{ Sex } & \multicolumn{2}{c}{ Age (years) } & \multirow{2}{*}{ Total } \\
\cline { 2 - 4 } & $\leq 40$ years & $>40$ & \\
\hline Male & $6(85.71 \%)$ & $1(14.29 \%)$ & $7(100.0 \%)$ \\
Female & $5(33.33 \%)$ & $10(66.67 \%)$ & $15(100.0 \%)$ \\
\hline Total & 11 & 11 & 22 \\
\hline$\chi^{2}=5,00, \mathrm{df}=1, \mathrm{p}=0,0253<0.05$ &
\end{tabular}

There are no significant differences in health characteristics between gender of patients with dry eye for ICSEM (Table 4).

Table 4 Health characteristics of patients with dry eye for ICSEM

\begin{tabular}{lcccc}
\hline \multirow{2}{*}{ Sex } & \multicolumn{3}{c}{ Health characteristics } & \multirow{2}{*}{ Total } \\
\cline { 2 - 4 } & RA & HTA & DM & \\
\hline Male & 1 & 1 & 0 & 2 \\
& $(50.00 \%)$ & $(50.00 \%)$ & $(0.00 \%)$ & $(100.00 \%)$ \\
Female & 6 & 6 & 1 & 13 \\
& $(46.15 \%)$ & $(46.15 \%)$ & $(7.70 \%)$ & $(100.00 \%)$ \\
\hline Total & 7 & 7 & 1 & 15 \\
\hline
\end{tabular}

$\chi^{2}$ test, n.s.

Epithelial cells were presented as grouped and dense, intact in controls, or easily separated, weakly cohesive (Fig. 1 A), individual cells in the group with dry eye.

The degree of squamous metaplasia, estimated by nucleo/cytoplasmic relations, was unchanged if the ratio of the nucleus and cytoplasm was 1: 1 to 1:3, low grade with $1: 4$ to $1: 6$ ratio, expressed if the ratio was $1: 6$ to $1: 10$ and massive, if the ratio of these parameters was more than 1:10 in group with dry eye (Fig. $1 \mathrm{~B}$ ). The degree of keratinization was low grade when there were few keratinocytes, or expressed and massive, if the sample exceeds the number of cytological nonkeratinization cells in group with dry eye. Nuclear changes were evaluated based on the shape of sails, including the "serpentine sails" as a marked characteristic of squamous metaplasia in dry eye syndrome (Fig. 1A-C); a frequency change was graded according to the number of changed nuclei (sporadic, few and plenty of altered nuclei). Goblet cells were evaluated by number - normally present or easily reduced in group with dry eye, expressed a smaller 

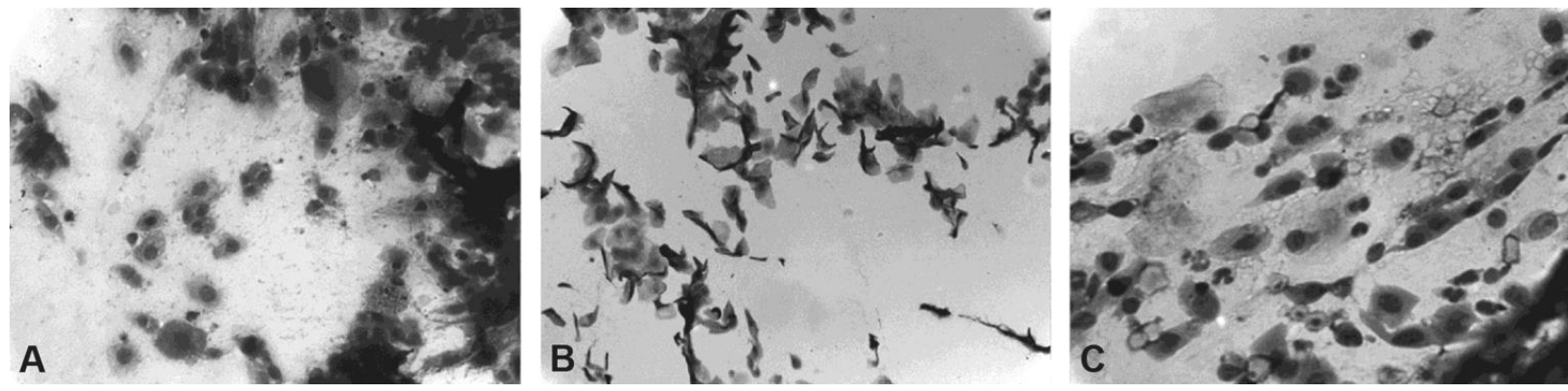

Fig. 1 A, B, C Cytomorphological feature of bulbar conjunctiva in CIC samples

number, sporadically or not found in the cytological sample. Morphological changes of goblet cells were evaluated for content as the normal mucous cells without mucus, a moderate reduction of the content and with abundant mucus. Mucus quality was assessed as normal if it is granular, seen with exudates, filaceous or in the aggregate. Inflammatory cells are described if they are present and the quantity of the sample.

The ten morphological parameters of IC samples were explored: the ratio of the cohesion of the epithelial cells, the degree of squamous metaplasia, degree of keratosis, frequency of nucleus changes, the type of nuclear changes, goblet cell density, morphology of goblet cells, the amount of mucus, mucus morphology and the presence of inflammatory cells.

The results of semi quantitative analysis of these parameters between controls and the group with dry eye, showed no significant differences in IC score on the nasal and temporal localization, except that the presence of inflammatory cells in both examined localizations is statistically more frequent in controls than in the study group $\left(\chi^{2}=13.61, \mathrm{p}=0.0035, \mathrm{p}<0.01\right.$ in the nasal and $\chi^{2}=12.50, \mathrm{p}=0,0059, \mathrm{p}<0.01$ in the temporal localization).

Characteristics of epithelial sheets were analyzed in controls and the group with dry eye on the basis of intactness, or the presence of reduced cohesion, severe levels of reduced cohesion or the findings of individual cells. There was no statistical significance between controls and the group with dry eye in the characteristics of epithelial sheets on the nasal IC scores $\left(\chi^{2}=1.66, \quad \mathrm{p}=0.6445\right)$ and temporal localization $\left(\chi^{2}=0.46, \quad \mathrm{p}=0.9270\right)$. Squamous metaplasia and keratinization were low grade, expressed or massive. There was no statistically significant difference between controls and group with dry eye in the nasal $\left(\chi^{2}=0.88\right.$, $\mathrm{p}=0.8296)$ and temporal localization $\left(\chi^{2}=0.70, \mathrm{p}=\right.$ 0.8726 ) for presence of keratinization as well as squamous metaplasia (nasal $\chi 2=0.80, \mathrm{p}=0.8500$, and temporal $\left.\chi^{2}=1.38, \mathrm{p}=0,7111\right)$. Nuclear changes were graded as sporadic, several or extensive. It is evident that the nuclear changes are presented in group with dry eye in both localizations (especially temporal), but no statistically significant differences were proven compared to the control group $\left(\chi^{2}=1.26, p=0.7394\right.$ the nasal localization and $\chi^{2}=2.40, p=0.4929$ in temporal localization). The type of nuclear changes was classified low grade, chromatin snake $1+2+$ forms and nuclear fragmentation. It is evident that the nuclear changes represented in the group with dry eye in both localizations (especially temporal), but no statistically significant differences were found compared to controls $\left(\chi^{2}=1.66, p=0.6450\right.$, the nasal localization and $\chi^{2}=1.78$, $\mathrm{p}=0.6197$ in temporal localization). Goblet cell density was normal or reduced. Even if the normal density of goblet cells was present in the control group, no significant differences in the density of goblet cells were found in relation to the group with dry eye in both localizations, nasal and temporal $\left(\chi^{2}=1.35, \mathrm{p}=0.7181\right.$, in the nasal localization and $\chi^{2}=2.67, p=0.4459$, in temporal localization) as well as the morphology of goblet cells in both groups $\left(\chi^{2}=0.09, \mathrm{p}=0,7646\right.$ the nasal and temporal localization). The amount of mucus is normal or abnormal - heavy, medium and absent. There were no statistically significant differences in the amount of mucus between control group and group with dry eye in the nasal and temporal localization $\left(\chi^{2}=0.92\right.$, $\mathrm{p}=0.8210$, in the nasal and $\chi^{2}=0.75, \mathrm{p}=0.8614$, in temporal localization).

Mucus quality was considered normal if it was granular, with exudate, filamentous or in aggregate. Statistically significant differences were not present in morphology of the mucus of the controls and group with dry eye in the nasal and temporal localization $\left(\chi^{2}=0.56\right.$, $\mathrm{p}=0.7547$ the nasal localization and $\chi^{2}=0.67, \mathrm{p}=0$, 7135 the temporal localization).

Among the twenty two persons for ICSEM, 7 were male and 15 female (Table 3). The largest was the oldest category of subjects $>40$ years, $n=11$. The diagnosis of dry eye was established in 15 people according to the following clinical criteria: Schirmer I $\leq 10 \mathrm{~mm} / 5 \mathrm{~min}$; TBUT $\leq 10 \mathrm{sec}$; Rose Bengal positive, 3 of 4 per Bijsterveld. This group included patients with rheumatoid arthritis (RA), hypertension (HTA), and diabetes mellitus (DM) (Table 4).

In physiological conditions, all epithelial types of the conjunctiva showed good cohesiveness, as well as exchange of information upon contact, tubular formations with high electron density which, like probes, penetrate adjacent cells. They are located along lateral cellular walls and are more expressed in younger population and in control groups (Fig.2A i C). These 

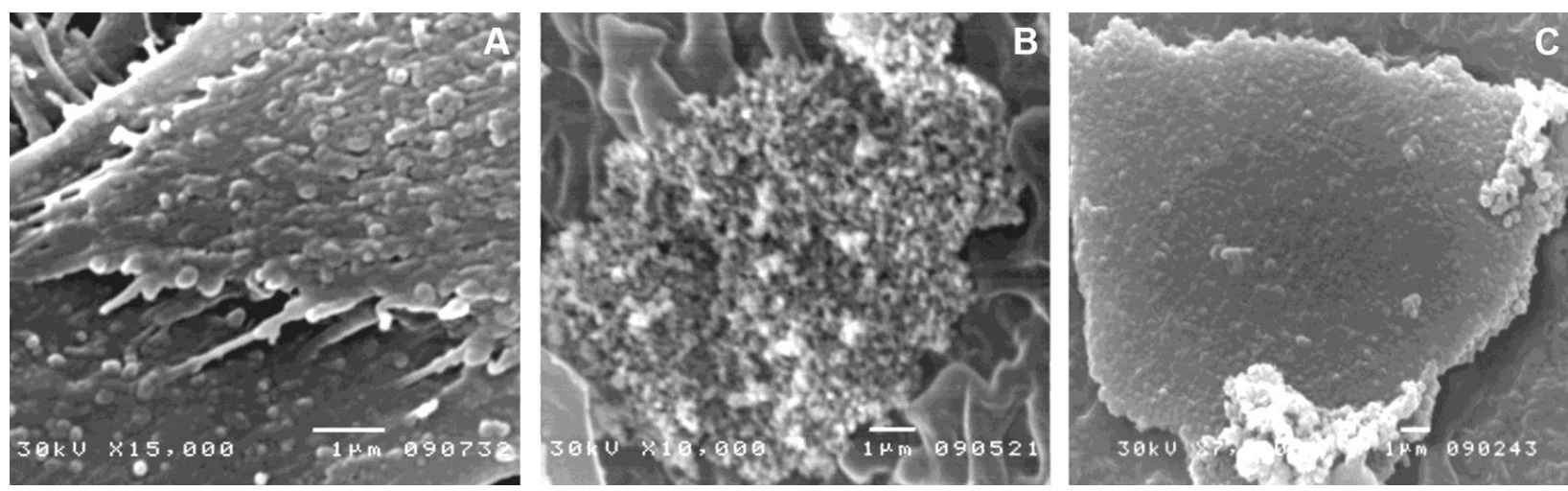

Fig. 2 A, B, C. Epithelial cells in physiological conditions (2 A et 2 C), tears (2 B)

structures are abundant in tear film after adverse factors. They are completely absent in pathological conditions.

The tear film presents as abundant granulated mass with dominant complex protein molecules or as filamentous structure, sometimes as lumpy protein mass containing crystal formations of cuboid sodium salts (Fig.2B).

In middle-aged and older patients (Fig. $3 \mathrm{~A}, \mathrm{~B}, \mathrm{C}$ ), apical surfaces lose the cytoplasmic and membranous ectropion, the cohesiveness is age-dependent and proportionate to exposure to the factors from external and internal environment - the severity of the damage of lateral conjunctiva gradually increases towards the nasal part. The number of cells with rough creases in the apical surface is proportionately higher and there are also keratin cells, which are typically small, robust, rough, individually distributed in filter paper imprint. The decrease in epithelial cohesiveness is manifested as widened intercellular connections and the findings of individual cells in the imprint.

The tear film is detected as a mass of rough protein and mineral deposits.

In patients with dry eye (Fig. 4 A, B, C), the number and distribution of cellular formations is contrary to the findings obtained from the control groups and young examinees. The dominant cells are those with rough morphology, robust squamous metaplastic epithelial cells, with smaller dimensions than normal conjunctival
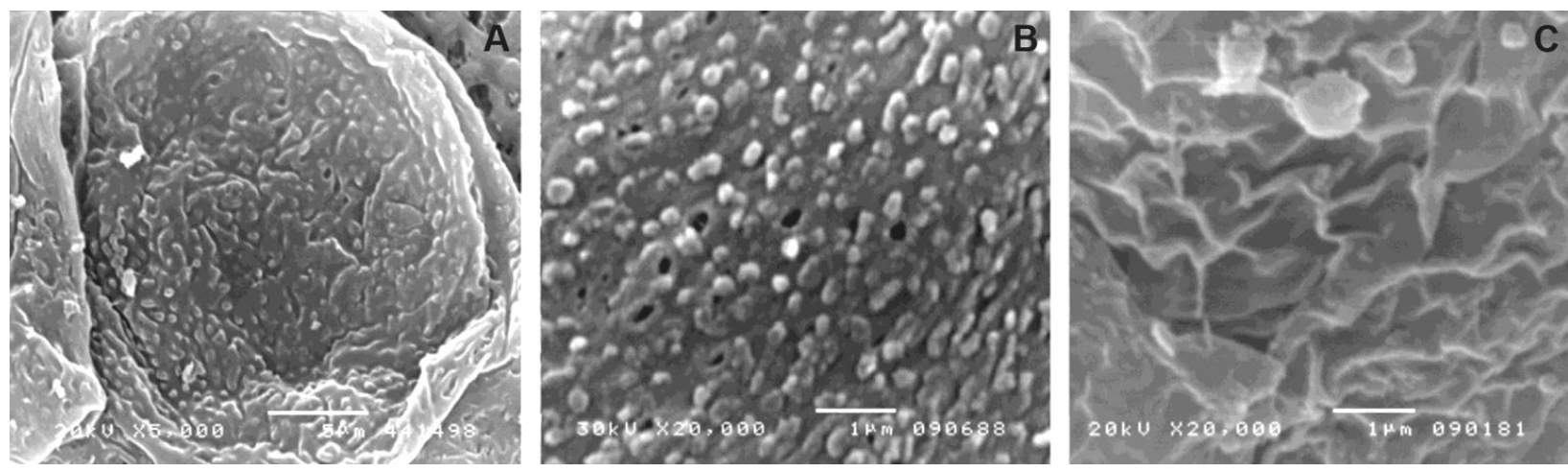

Fig. 3 A, B, C. Epithelial cells look like "cut stone" in older age patient group
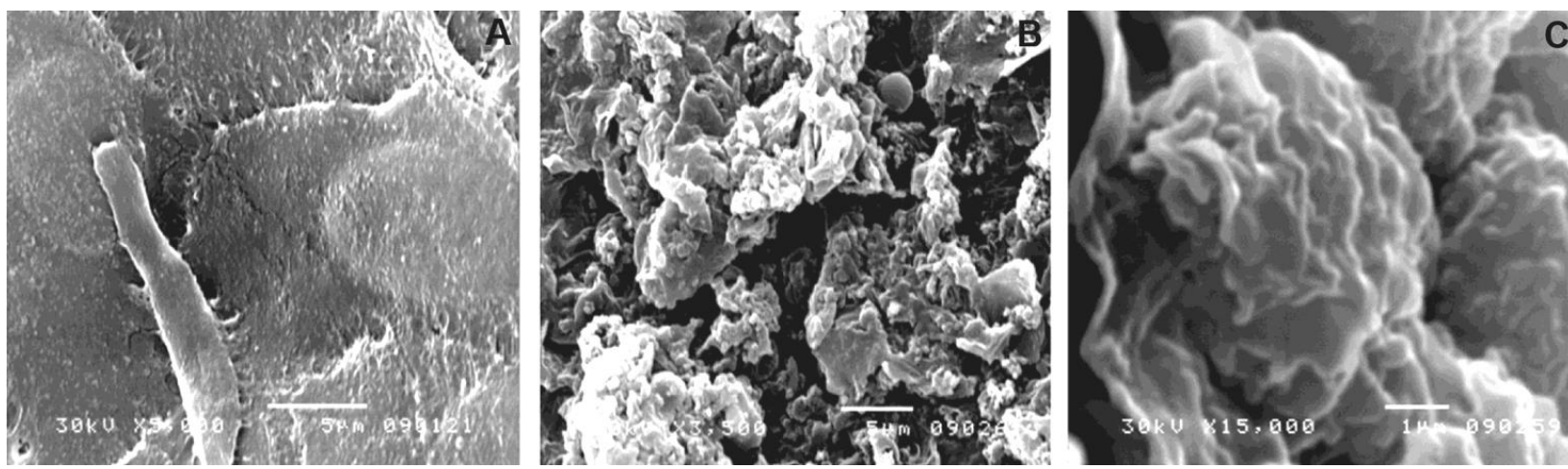

Fig. 4 A, B, C. Epithelial cells in patients with dry eye 
cells. If present, villous cells are sparse and very often only rare, individual cells are obtained from the sample.

The fissured defect of the cell membrane after separation of the microvillus is a focal change, although diffuse defects have also been observed, which show a latticelike profile of the apical membrane. Under these circumstances, adverse environmental factors have a twofold effect - toxic and metaplasia induced by phenotype change in altered circumstances. Cells with rough and more expressed creases are found, which is the result of volume reduction or the first sign of evaporation caused by tear film defect.

\section{Disscusion}

Tear film and ocular surface is a complex and stable system whose equilibrium can be disrupted by many factors $[1,9,13,14]$.

In dry eye syndrome the conjunctiva of our patients showed progressive stratification, hyperplasia with thinning and cell metaplasia. The appearance of binuclear cells or "incisions sails" in the cells can be seen in the early stages of this condition, while the form of pyknotic nuclei or loss of nuclei is a characteristic of the disease in advanced stage, which is similar to the results of other authors [15]. Separation of the epithelium is linear and follows the degree of severity of the syndrome. Reduced the number of goblet cells is a part of integrated morphological changes of the conjunctiva in relation to age changes, and that is not an isolated factor that contributes to the presence and / or highlighting the phenomenon of dry eye.

The ICSEM is an analysis of all available cells in cytological samples of the conjunctiva. This method of cytomorphological examination shows that except architectural changes, epithelial changes include a change in phenotype of cells of the conjunctiva. In the youngest category of subjects, the dominant epithelial types in the conjunctiva are gentle and rich villous structures without goblet cells, in the middle and older ages there were voluminous, cubic cells, with roughly wavy apical membrane surface, rounded and villous. The representation of both cell types was uneven and with variations in number, compared to age but not gender. In patients with dry eye and DM, HTA, RA these changes build on squamous metaplasia, inflammation and severe loss of adhesiveness of the epithelium. The appearance of papillary epithelial structures and focal irregular proliferation of cells with squamous metaplasia, and loss of adherence of the epithelium were observed in all analyzed groups of elderly patients.

The analysis of histological and cytological characteristics of the conjunctiva in relation to the age points to the main morphological features of the conjunctiva. It was noted that the number of epithelial sequences increases with age, while the number of goblet cells decreases. This adaptive phenomenon reflects the need for protection from external influences, or the response to proliferative stimuli from the environment. These findings agree with the findings from other authors[11, 12,15,16-22,24-26], but aging as a key factor for the appearance of dry eye syndrome was established in numerous studies [2, 24,25, 27,28].

Squamous metaplasia is a condition in which the nonkeratinized epithelium is replaced with keratinized epithelium. It is a common pathological process in most epithelia, including the respiratory epithelium and the urothelium and it is a frequent occurrence in diseases with manifestations of dry eye, such as Sjögren's syndrome, Steven-Johnson syndrome, pemphigoid mucous membranes, and thermal eye injuries [15,18,29]. According to the findings, epithelial hyperplasia was observed, a process associated with aging and the continuous change of the epithelium which is seen in people with DM and RA.

Hyperplasia with squamous metaplasia of the epithelium is accompanied by a change in keratin expression and as shown in research, it comes exclusively from limbal stem cell pool, which involves transdifferentiation of terminally differentiated cells [30]. This study has shown that the phenomenon of metaplasia is present in the bulbar conjunctival epithelium in the absence of manifested dry eye, which forms the basis for understanding the increased incidence of this syndrome in the elderly. Transdifferentiation inhibitors can also be used as prophylaxis during life.

\section{Conclusion}

The ocular surface is a delicate and vulnerable structure. Investigation of the component parts of the ocular surface must necessarily be done without disruption (or at least minimal invasion) of physiological function.

The analysis of CIC parameters is a non-aggressive, reliable and representative method in the diagnosis of dry eye and can be used as a screening test for vulnerable age groups and persons at risk for developing the dry eye syndrome. Combined ICSEM methods show the evolution of conjunctival epithelial lesions. The advantage of this method is the identification of conjunctival epithelial damage which disrupted the tear film before the epithelial damage can be detected by optical microscopy.

A timely diagnosis of dry eye syndrome allows the application of adequate treatment and implementation of preventive therapy. Better knowledge of the pathophysiology and diagnosis of dry eye allows better and more effective treatment of dry eye. 


\section{References}

1. Brewit H, Sistani F. Dry eye disease: the scale of the problem. Surv Ophthalmol 2001; 45:199-202.

2. Perry H.D. Dry eye disease: pathophysiology, classification, and diagnosis. Am J Manag Care 2008; 14:79-87.

3. Stern ME, Schaumburg CS, Pflugfelder SC. Dry eye as a mucosal autoimmune disease. Int Rev Immunol 2013; 32(1): 19-41. doi: 10.3109/08830185.2012.748052

4. Schaumberg DA, Sulliuvan DA, Buring JE, Dana MR. Prevalence of dry eye syndrome among US women. Am J Ophthalmol 2003; 136:318-326.

5. Vitale S, Goodman LA, Reed GF, Smith JA. Comparison of the NEI-VFQ and OSDI questionnaires in patients with Sjögren's syndrome-related dry eye. Health Qual Life Outcomes 2004; 2 : 44.

6. Chia EM, Franzco PM, Rochtchina E, Lee AJ, Maroun R, Wang JJ. Prevalence and associatiations of dry eye syndrome in an older population: the Blue Mountains Eye Stydy. Clin Exp Ophthalmol 2003; 31:229-232

7. Patel S, Blades JK. The dry eye. A Practical Approach. Butterworth-Heinemann, 2003; 14-65.

8. Egbert PR, Lauber S, Maurice DM. A simple conjunctival biopsy. Am J Ophthalmol 1977; 84:798-801

9. Mc Kelvie, P. Ocular surface impression cytology. Adv Anat Pathol 2003; 10:328-337.

10. Singh R, Joseph A, Umapathy T, Tint NL, Dua SH. Impression cytology of the ocular surface. $\mathrm{Br} \mathrm{J}$ Ophthalmol 2005; 89:1655-1659.

11. Cennamo GL, Del Prete A, Fort R, Cafiero G, Del Prete S, Marasco D. Impression cytology with scanning electron microscopy: a new method in the study of conjunctival microvilli. Eye 2008; 22(1):138-143.

12. Haller-Schober E-M, Schwantzer G, Berghold A, Fisch M, Theisl A, Horwath-Winte J. Evaluating an impression cytology grading system (IC score) in patients with dry eye syndrome. Eye 2006; 20:927-933.

13. Versura P, ProfazioV, Cellini M, Torreggiani A, Caramazza R. Eye discomfort and air pollution. Ophthalmologica 1999; 213(2):103-109.

14. Abelson MB, Ousler GW. Ocular Protection Index. Dry Eye Expert Summit. Rev of Ophthalmol 2003; 2:15.

15. Marner K. Snake-like appearance of nuclear chromatin in conjunctival epithelial cells from patients with keratoconjunctivitis sicca. Acta Ophthalmol (Copenh) 1980; 58:849-853.
16. Calonge M, Diebold Y, Sáez V, Enríquez de Salamanca A, Garsía-Vázquez C, Corrales RM, et al. Impression cytology of the ocular surface - a review. Exp Eye Res 2004; 78:457-472.

17. Torok M, Suveges I. Morphological changes in »dry eye syndrome«. Grafe's Arch Clin Exper Ophtalmol 1982; 219: 24-28.

18. Kinoshita S, Kiorpes TC, Friend J, Thoft RA. Goblet cell density in ocular surface disease. Arch Ophthalmol 1983; 101: 1284-1287.

19. Murube J, Rivas L. Biopsy of the conjuctiva in dry eye patients establishes a correlation between squamous metaplasia and dry eye. Eur J Ophtalmol 2003; 13:246-256.

20. Wittpenn JR, Tseng SC, Sommer A. Detection of early xerophthalmia by impression cytology. Arch Ophthalmol 1996; 104:237-239.

21. Sternlicht MD, Werb Z. How matrix metalloproteinases regulate cell behavior. Annu Rev Cell Dev Biol 2001; 17: 463-516.

22. Thoft RA, Friend J, Kinoshita S, Nikolic L, Foster S. Ocular cicatricial pemphigoid associated with hyperproliferation of the conjunctival epithelium. Am J Ophthalmol 1984; 98:37-42.

23. Kinoshita S, Adachi W, Sotozono C, Nishida K, Yokoi N, Quantok AJ,et al. Characteristics of the human ocular surface epithelium. Prog Ret Eye Res 2001; 20(5):634-639.

24. Moss SE, Klein R, Klein BEK. Incidence of Dry Eye in an Older Population. Arch Ophthalmol 2004; 122:369-373.

25. Moss SE, Klein R, Klein BEK. Prevalence of and Risk Factors for Dry Eye Syndrome. Arch Ophthalmol 2000; 118: $1264-1268$.

26. Vujković V, Mikač G, Kozomara R. Distribucija i gustina peharastih ćelija u konjunktivi. Med Preg 2002; 5-6:195-200.

27. Jie Y, Xu L, Wu YY, Jonas JB. Prevalence of dry eye among adult Chinese in the Beijing eye study. Eye 2008;23: 688-693.

28. Mc Carty CA, Bansal AK, Livingston PM, Stanislavsky YL, Taylor HR. The epidemiology of dry eye in Melbourne, Australia. Ophthalmol 1998; 105:1114-1119.

29. Sangwan VS, Tseng CG. New perspectives in ocular surface disorders. An integrated approach for diagnosis and management. Ind J Ophtalmol 2001; 49:152-168.

30. Wei L, Hayashida Y, Ying-Ting C, Hua H, David YT, Morgan A et.al. Air Exposure-Induced Squamous Metaplasia of Human Limbal Epithelium. Invest Ophthalmol Vis Sci 2008; 49(1): 154-162. 